\title{
вмJ Global Health Variation in neonatal mortality and its relation to country characteristics in sub-Saharan Africa: an ecological study
}

\author{
Gbenga Ayodele Kayode, ${ }^{1,2}$ Diederick E Grobbee, ${ }^{1,3}$ Mary Amoakoh-Coleman, ${ }^{1,4,5}$
} Evelyn Ansah, ${ }^{6}$ Olalekan A Uthman, ${ }^{7,8}$ Kerstin Klipstein-Grobusch ${ }^{1,9}$

To cite: Kayode GA,

Grobbee DE,

Amoakoh-Coleman M, et al. Variation in neonatal mortality and its relation to country characteristics in subSaharan Africa: an ecological study. BMJ Glob Health 2017;2:e000209. doi:10.1136/ bmjgh-2016-000209

Handling editor Seye Abimbola

Received 8 0ctober 2016 Revised 27 August 2017 Accepted 2 September 2017

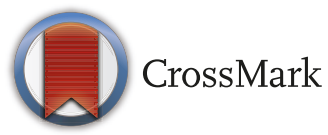

For numbered affiliations see end of article.

Correspondence to Dr Gbenga Ayodele Kayode; gakayode@yahoo.co.uk

\section{ABSTRACT}

Background A substantial reduction in neonatal mortality is the main priority to reduce under-five mortality. A clear understanding of the variation in neonatal mortality and the underlying causes is important for targeted intervention. We aimed to explore variation in neonatal mortality and identify underlying causes of variation in neonatal mortality in sub-Saharan Africa (SSA).

Methods This ecological study used 2012 publicly available data from WHO, the US Agency for International Development and the World Bank. Variation in neonatal mortality across 49 SSA countries was examined using control chart and explanatory spatial data analysis. Associations between country-level characteristics and neonatal mortality were examined using linear regression analysis.

Results The control chart showed that 28 (57\%) SSA countries exhibited special-cause variation, 14 countries were below and 14 above the $99.8 \%$ control-limits. The remaining 21 (43\%) SSA countries showed commoncause variation. No spatial clustering was observed for neonatal mortality (Global Moran's I statistic -0.10 ; $p=0.74)$. Linear regression analysis showed HIV/AIDS prevalence among the population of reproductive age to be positively associated with neonatal mortality $(\beta=0.463$; $95 \% \mathrm{Cl} 0.135$ to $0.790 ; \mathrm{p}<0.01$ ). Declining socioeconomic deprivation ( $\beta=-0.234 ; 95 \% \mathrm{Cl}-0.424$ to -0.044 ; $\mathrm{p}<0.05)$ and high quality of healthcare governance $(\beta=-1.327,95 \% \mathrm{Cl}-2.073$ to $-0.580 ; p<0.01)$ were inversely associated with neonatal mortality.

Conclusion This study shows a wide variation in neonatal mortality in SSA. A substantial part of this variation can be explained by differences in the quality of healthcare governance, prevalence of HIV and socioeconomic deprivation. Future studies should validate our findings using more rigorous epidemiological study designs.

\section{BACKGROUND}

A substantial reduction in neonatal mortality is one of the main priorities to realise sustainable development goal 3 (SDG 3-aims to ensure healthy lives and promote well-being for all at all ages) given that neonatal death accounts for $40 \%$ of under-five mortality. Globally, about 10000 neonates are dying daily, ${ }^{2}$ an estimate that may be significantly higher considering the likelihood of

\section{Key questions}

What is already known about this topic?

- Previous studies have linked variation in neonatal mortality with paternal, maternal, neonatal and socioeconomic factors at individual-level.

- In addition, experts in neonatal health have advocated for increase in health financing, healthcare coverage and other interventions as means of improving survival in early life.

What are the new findings?

- This study determined the impact of healthcare governance on neonatal survival, which no previous studies have examined.

- Increase in healthcare coverage and financing without good quality of healthcare governance may not improve neonatal survival.

Recommendations for policy

- As governments in SSA is increasing health financing, health human resources and health service coverage, it is important to improve the quality of healthcare governance to avoid wastage.

under-reporting, ${ }^{3}{ }^{4}$ especially in low-income and middle-income countries. ${ }^{5}$ Sub-Saharan Africa (SSA) has the highest rate of neonatal mortality worldwide ${ }^{6}$ with some degree of variation across SSA countries and only minor declines over the last two decades. ${ }^{3}$ Examining variation in health outcomes across similar settings is an important aspect of epidemiological research to guide assessment of inequality in health outcomes, ${ }^{78}$ health system performance monitoring ${ }^{9-11}$ and healthcare governance. ${ }^{12}$

Exploring variation in health outcome requires collection of valid data, appropriate application of statistical analyses and adequate knowledge of exploring variation. Several studies emphasised the approach proposed by Shewhart and Deming on how to investigate and deal with variation. ${ }^{13-15}$ According to their findings, variation is a product of multiple 
Table 1 Descriptive characteristics of 49 sub-Saharan African countries

Country characteristics

\begin{tabular}{|c|c|}
\hline Neonatal mortality (per 1000 live births) & $30.1(9.8 ; 8$ to 50$)$ \\
\hline HIV prevalence (\%) & $4.9(6.5 ; 0.2$ to 26.5$)$ \\
\hline Health financing (US\$ per person) & $209.6(313.4 ; 17$ to 1642.7$)$ \\
\hline Physicians per 1000 people & $0.2(0.28 ; 0.01$ to 1.51$)$ \\
\hline Nurses and midwives per 1000 people & $1.1(1.46 ; 0.03$ to 7.92$)$ \\
\hline Contraceptive prevalence (\%) & $28.1(19.3 ; 4$ to 75.9$)$ \\
\hline Skilled delivery (\%) & $59.1(21.9 ; 10$ to 99.2$)$ \\
\hline Health governance (score ranged from -15 to +15 ) & $-4.1(3.8 ;-13.7$ to 5.0$)$ \\
\hline Country socioeconomic status & $56.0(14.9 ; 29.5$ to 95.9$)$ \\
\hline Literacy rate (\% of people aged 15 and above) & $65.0(19.1 ; 27$ to 94.2$)$ \\
\hline
\end{tabular}

factors, and every system is subjected to both common (expected) and special-cause (unexpected) variation. This concept has been applied in health system research. ${ }^{9} 16$

In common-cause variation, it is expected that the deviation of the estimated health outcome for a particular setting should be within 3 standard deviations (SD) of the overall average of the estimated health outcome for all settings. ${ }^{13}$ In other words, the estimated health outcome should be within so-called 'control limits'. ${ }^{13}$ Although such variation is referred to as common-cause variation, it does not imply that the causes of variation are identical across the settings within the control limits, but that a combination of different multiple factors might have influenced the observed health outcome in these settings. Thus, the combined effect of these multiple factors on health outcome for each population is similar, because the effect estimates are all within the control limits.

In case of special-cause variation, the health outcome of that setting is expected to be outside the $3 \mathrm{SD}$ of the overall average of the estimated health outcomes for all the settings. Factors responsible for such variation usually have an unexpected high impact on the observed health outcome. To thoroughly examine variation in health outcome across different populations, revealing the existence of common-cause and special-cause variation is a key aspect. In addition, it is important to visualise spatial

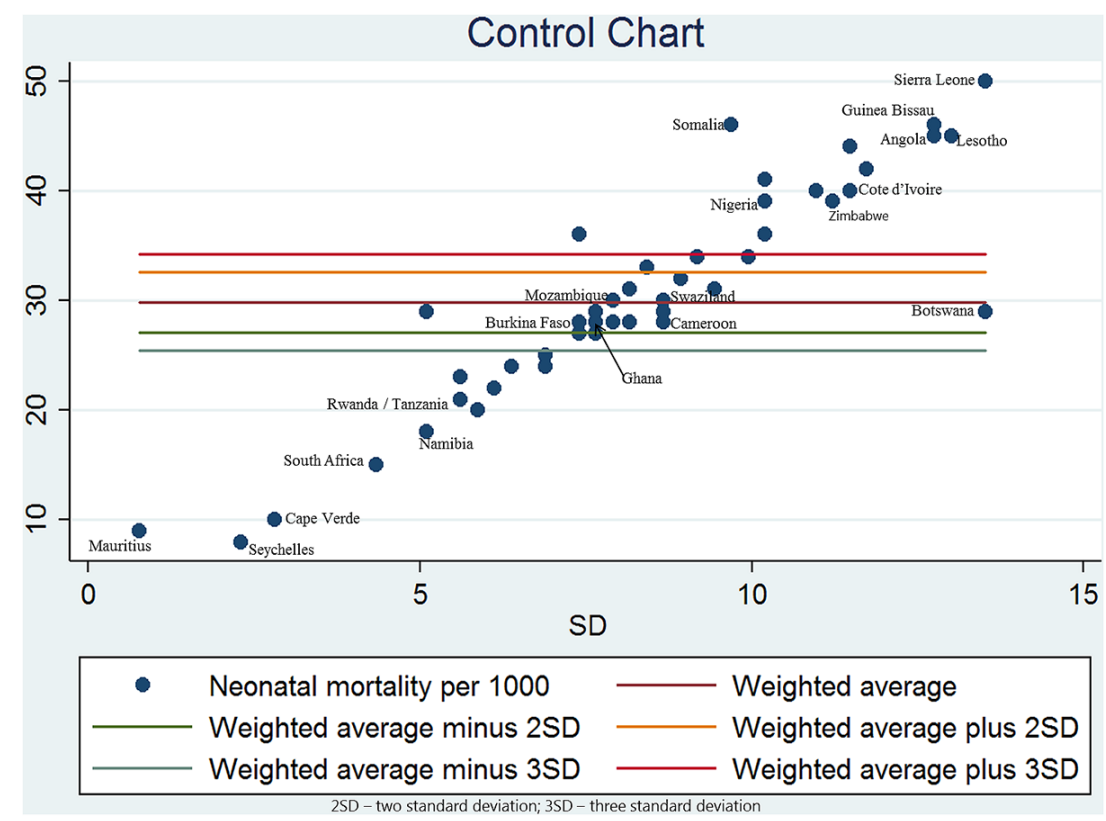

Figure 1 Control chart. 
Table 2 Global and local spatial autocorrelation for neonatal mortality in sub-Saharan Africa

\begin{tabular}{|c|c|}
\hline Country & $\begin{array}{l}\text { Local Moran's } \\
\text { I statistic ( } p \text { value) }\end{array}$ \\
\hline Angola & $-0.2034(0.6473)$ \\
\hline Benin Republic & $-0.0077(0.4859)$ \\
\hline Botswana & $0.2638(0.2713)$ \\
\hline Burkina Faso & $-0.0706(0.5488)$ \\
\hline Burundi & $-0.1874(0.6139)$ \\
\hline Cameroon & $-0.1784(0.6588)$ \\
\hline Central Africa Republic & $0.3505(0.1849)$ \\
\hline Chad & $0.1301(0.3559)$ \\
\hline Côte d'Ivoire & $-0.0065(0.4829)$ \\
\hline Congo Brazzaville & $0.0095(0.4677)$ \\
\hline Congo Democratic Republic & $-0.1832(0.7052)$ \\
\hline Djibouti & $0.0103(0.4750)$ \\
\hline Equatorial Guinea & $-0.1604(0.5785)$ \\
\hline Eritrea & $0.4242(0.2089)$ \\
\hline Ethiopia & $0.0662(0.4142)$ \\
\hline Gabon & $0.0502(0.4464)$ \\
\hline Gambia & $0.4236(0.3243)$ \\
\hline Ghana & $-0.0975(0.5525)$ \\
\hline Guinea Liberia & $0.1890(0.2854)$ \\
\hline Guinea-Bissau & $-0.5647(0.7843)$ \\
\hline Kenya & $0.1532(0.3354)$ \\
\hline Lesotho & $-3.0964(0.9991)$ \\
\hline Liberia & $-0.6433(0.8681)$ \\
\hline Malawi & $0.5700(0.1416)$ \\
\hline Mali & $-0.0743(0.5527)$ \\
\hline Mauritania & $0.0342(0.4660)$ \\
\hline Mozambique & $0.1434(0.3279)$ \\
\hline Namibia & $0.0885(0.3935)$ \\
\hline Niger & $-0.1910(0.6549)$ \\
\hline Nigeria & $-0.0856(0.5514)$ \\
\hline Rwanda & $0.1301(0.3721)$ \\
\hline Senegal & $-0.5428(0.8926)$ \\
\hline Sierra Leone & $-0.3441(0.6792)$ \\
\hline Somalia & $-0.5647(0.8354)$ \\
\hline South Africa & $0.0056(0.4682)$ \\
\hline Sudan & $0.0057(0.4651)$ \\
\hline Swaziland & $0.2429(0.3486)$ \\
\hline Tanzania & $0.3956(0.0925)$ \\
\hline Uganda & $-0.0616(0.5268)$ \\
\hline Togo & $0.4280(0.1396)$ \\
\hline Zambia & $0.0242(0.4390)$ \\
\hline Zimbabwe & $-0.7644(0.9617)$ \\
\hline
\end{tabular}

Global Moran's I statistic $=-0.0925 ; p=0.7393$, Geary's C statistic $=1.0640 ; p=0.7116$. distribution of health outcomes across populations and settings to detect any unusual pattern in terms of spatial clustering and outliers. Findings from such investigations may provide evidence to formulate targeted interventions aimed to improve health outcomes. ${ }^{17} 18$

Beyond the assessment of variation in neonatal mortality across SSA, the current study seeks to identify underlying factors that could explain the variation in neonatal mortality by considering country characteristics such as quality of healthcare governance, health financing, human health resources, health service delivery and the country's socioeconomic status. As SSA accommodates almost $70 \%$ of all people living with HIV globally ${ }^{19}$ with $>500000$ newborns infected annually, ${ }^{20}$ we considered the prevalence of HIV among the population of reproductive age as a potential factor to explain variation in neonatal mortality.

\section{METHODS}

\section{Study design and data collection}

This ecological study uses 2012 publicly available data from WHO, ${ }^{21}$ the US Agency for International Development ${ }^{22}$ and the World Bank ${ }^{23}$ repositories for 49 SSA countries. Aggregate data at country level on neonatal mortality, illiteracy and poverty rate, percentage of safe water coverage, improved sanitation facilities, HIV prevalence among the population of reproductive age (ie, 15-49 years), health governance, health human resources, health delivery and health financing were extracted.

\section{Study variables}

Outcome (dependent)

Neonatal mortality was defined as the number of deaths within the first 28 days of life per 1000 live births.

\section{Country-level characteristics (independent)}

Country-level characteristics considered to explain the underlying causes of variation in neonatal mortality were:

1. Prevalence of HIV infection among the population of reproductive age (ie, $15-49$ years);

2. Health financing based on per capita total expenditure on health at purchasing power parity (PPP) measured in US\$, that is, the ratio of total expenditure on health (private and public) and the total population; expressed in US\$ per person per year;

3. Health service delivery assessed by the average proportion of the population using contraceptives among women aged 15-49 years and births attended by skilled health staff;

4. Health human resources assessed by the average number of physicians and nurses per 1000 people;

5. Quality of health governance as assessed by political stability, government effectiveness, voice and accountability, rule of law, regulatory quality, political stability and control of corruption. Each of these six areas directly impacting health system operations was assessed based on points ranging from -2.5 to +2.5 ; higher points indicate better quality of health governance. Total health governance performance rating scores 

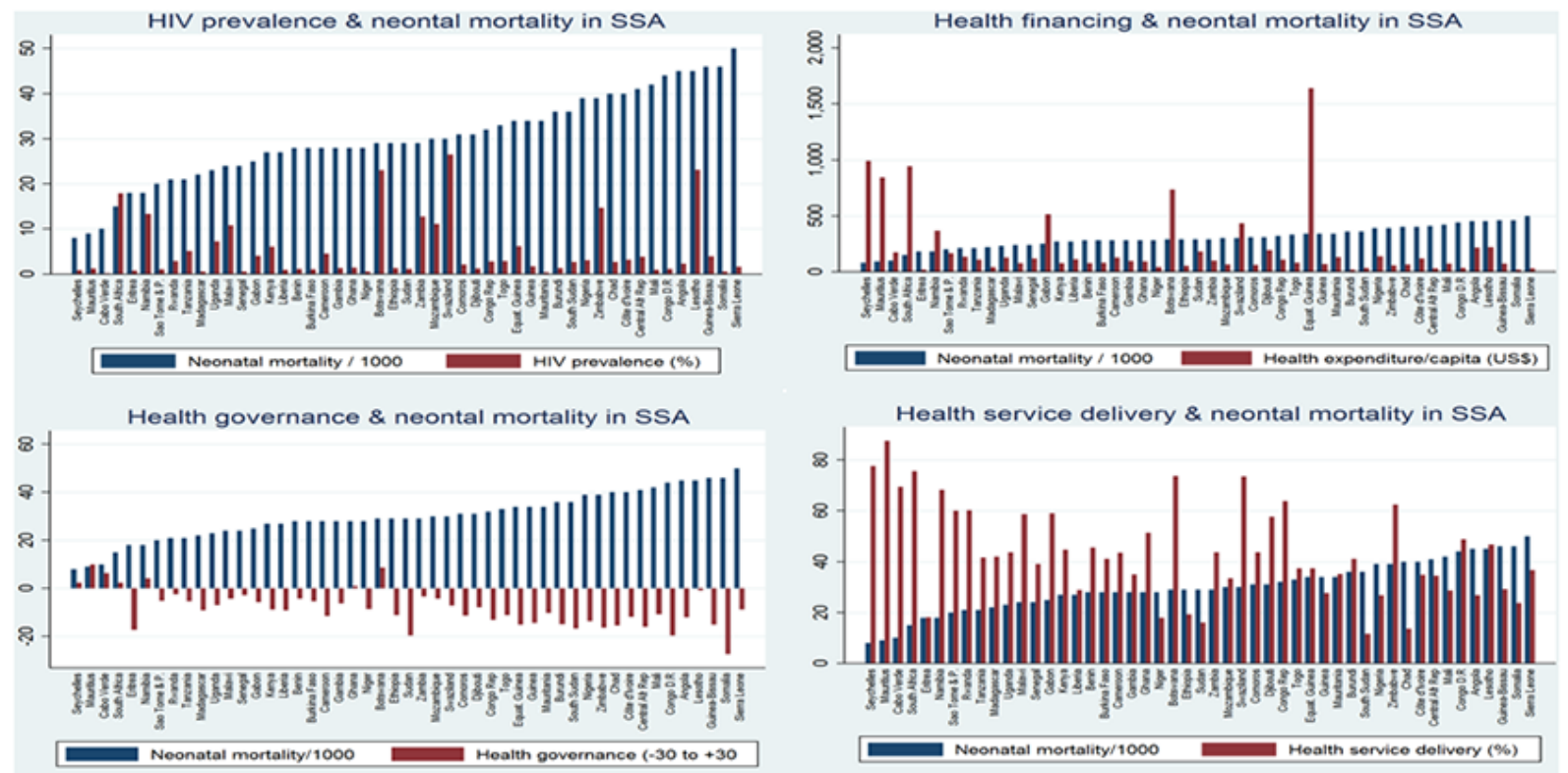

Health human resources \& neontal mortality in SSA
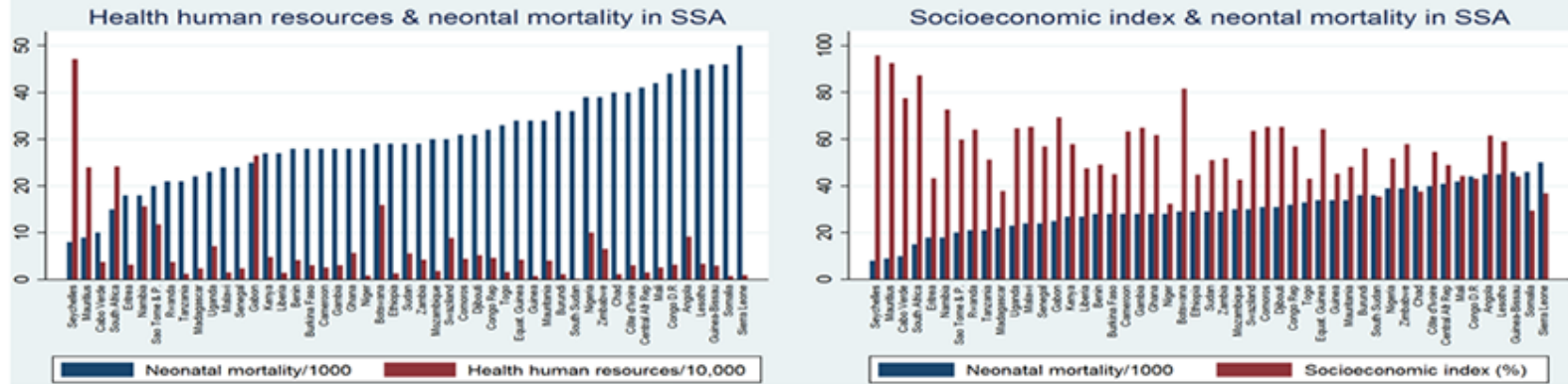

Figure 2 Relationships between country-level characteristics and neonatal mortality in sub-Saharan Africa (SSA).

range from -15 to +15 ; higher scores indicate better quality of health governance, respectively. Detailed information on assessment of health governance has been published elsewhere. ${ }^{24}$

6. Country's socioeconomic index was measured by use of the average proportion of the population that are literate, live above poverty and have access to safe water and improved sanitation facilities. Literacy rate was defined as the percentage of people aged 15 years and above who can read and write. Poverty rate was defined as the percentage of the population living below poverty line $(<\mathrm{US} \$ 1.25 /$ day $){ }^{22}$

\section{Statistical analysis}

Descriptive statistics

The range, mean and SD of neonatal mortality and country-level characteristics were estimated. A mixed-effect model was applied to estimate the weighted average of neonatal mortality using their variance as weight. Statistical analysis was performed using $\mathrm{R}$ statistical package. ${ }^{25}$

\section{Control chart}

A control chart was constructed by plotting neonatal mortality rates on the $y$-axis against a measure of their precision, that is, $\mathrm{SD}$ on the $\mathrm{x}$-axis. The chart has five horizontal lines, one central line with two lines below and above it. The central line indicates the overall neonatal mortality while the two additional lines at $95 \%$ limits $(\approx 2$ $\mathrm{SD})$ and $99.8 \%$ limits $(\approx 3 \mathrm{SD})$ on both sides of the central line represent $95 \%$ limits and $99.8 \%$ limits of the overall estimate of neonatal mortality. Countries with a neonatal mortality rate within the $99.8 \%$ control limits $(\approx 3 \mathrm{SD})$ are considered to show common-cause variation while those outside the $99.8 \%$ control limits are considered to exhibit special-cause variation. Statistical analysis was performed using Stata statistical package V.11. ${ }^{26}$

\section{Spatial data analysis}

Pfeiffer $e t a l$ and Anselin $e t$ al have described the application of Global Spatial Autocorrelation (GSA) and Local Indicators of Spatial Autocorrelation (LISA). ${ }^{27} 28$ In this study, we used Explanatory Spatial Data Analysis (ESDA) to estimate GSA that indicates overall clustering or non-randomness, that is, assessing the degree of overall similarity in the spatial pattern of neonatal mortality across SSA countries. Since GSA cannot express the degree of similarity between each country and its neighbouring countries with regard to neonatal mortality, we applied LISA to determine the presence of significant spatial patterns of neonatal mortality across SSA countries. Non-randomness in the spatial pattern of neonatal mortality was identified in terms of significant spatial clustering or outliers. The estimated Local Moran's I statistic was used to assess the significance 

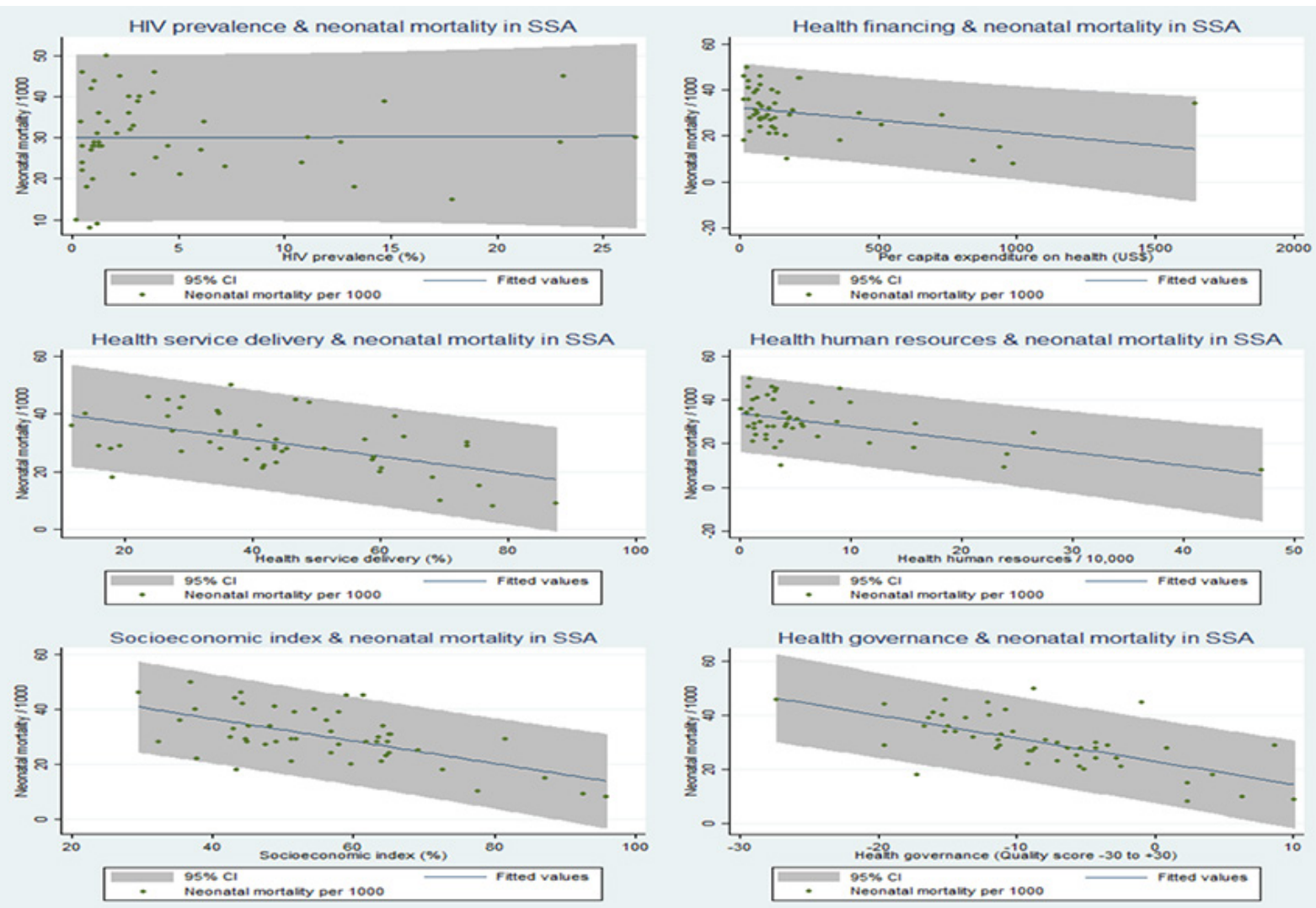

Figure 3 Unadjusted associations between country-level characteristics and neonatal mortality in sub-Saharan Africa (SSA).

of local clusters and outliers. Overall, four identifiable categories of local spatial association or local spatial autocorrelation can be observed: two categories indicate clustering while the other two suggest outliers. Hot spot local spatial association (clustering of countries with high incidence of neonatal mortality) and cold spot local spatial association (clustering of countries with low incidence of neonatal mortality) indicate clustering. High-low local spatial association (a country with high incidence of neonatal mortality surrounded by neighbouring countries with low incidence of neonatal mortality) and low-high local spatial association (a country with low incidence of neonatal mortality surrounded by neighbouring countries with high incidence of neonatal mortality) indicate outliers.

\section{Associations between country-level characteristics and neonatal mortality}

Associations between neonatal mortality and country-level characteristics were visualised by use of bar chart and two-way scatter plot with a prediction line and 95\% CI. Pairwise correlation test was used to determine the strength of the relationships between country-level characteristics and neonatal mortality. Based on the observed Moran's I statistic, spatial regression analysis was not considered ${ }^{29}$; instead a linear regression analysis was applied to examine the relationships between neonatal mortality and country-level characteristics. Univariable analysis was performed to examine the crude relationships between neonatal mortality and each country characteristic. Thereafter, all the prespecified country characteristics were included in a multivariable linear regression model. Model reduction was performed based on the significance of each variable and adjusted $R^{2}$, country characteristics that were now statistically significant were removed one after the other and the model that explained the observed variation in neonatal mortality best was determined based on the adjusted $\mathrm{R}^{2}$ statistics of the model. The underlying assumptions for linear regression analysis were checked. We used visual scatter plot to check for linearity relationship between the predictors and neonatal deaths per 1000 live births. Furthermore, we confirmed if the residuals were normally distributed and whether or not the model exhibited homoscedasticity using residual plot and White's test, respectively. In addition, Breusch-Pagan test was applied to confirm if the model exhibited homoscedasticity. Presence of multicollinearity was assessed using variance inflation factor and tolerance test. Statistical significance of the association was determined by two-tailed Wald test at significance level of alpha equal to $5 \%$.

\section{Ethical approval}

For analysis of anonymous publicly available data, no ethical approval is required. ${ }^{21} 23$

\section{RESULTS}

\section{Descriptive statistics}

The summary statistics of the 49 countries included in the analysis are shown in table 1 . Across countries neonatal 


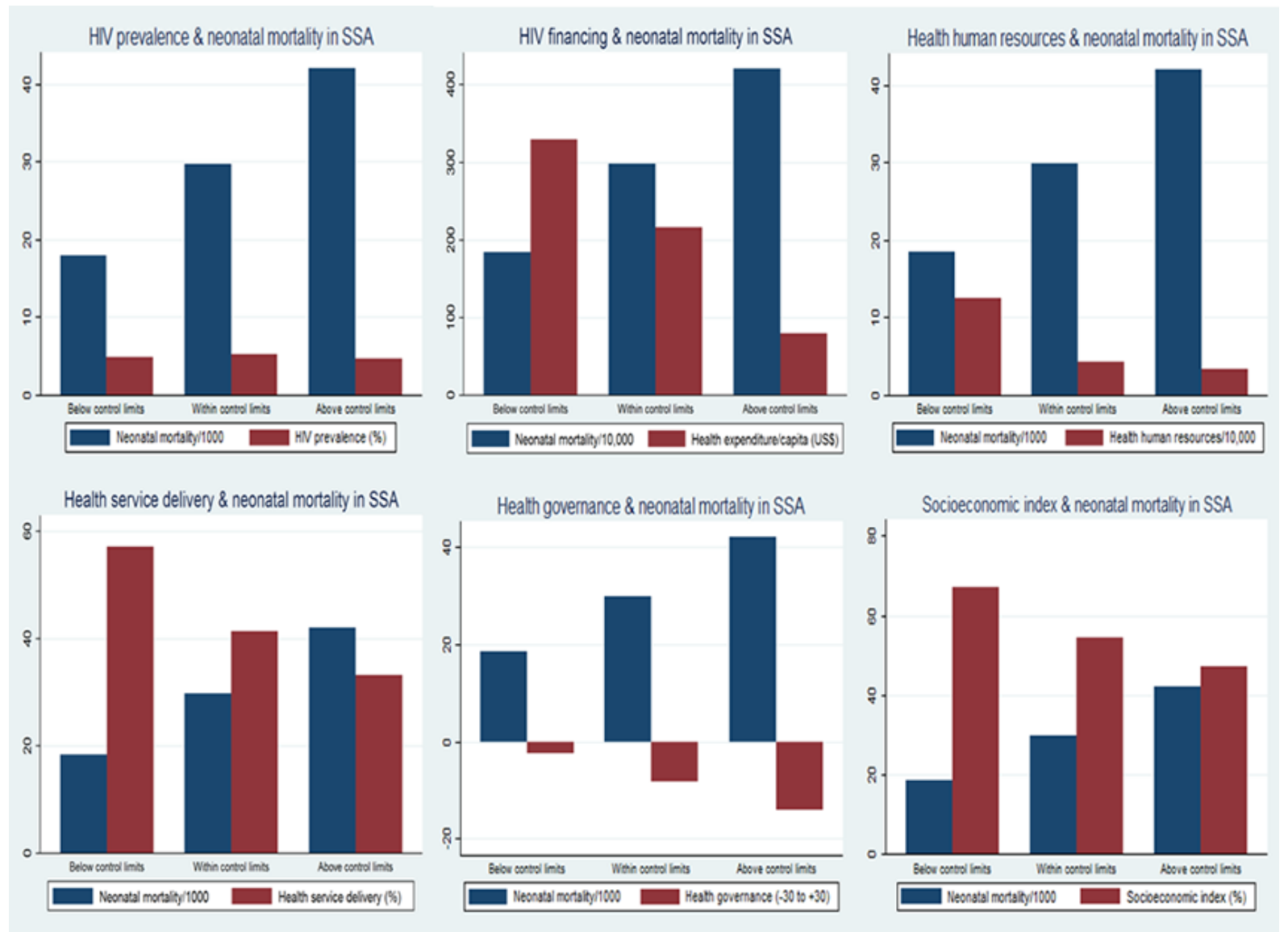

Figure 4 Relationships between country-level characteristics and neonatal mortality for countries below, within and above the control limits. SSA, sub-Saharan Africa.

mortality ranged from 8 to 50 per 1000 live births (average 30.1 per 1000 live births, SD 9.8 per 1000 live births). The prevalence of HIV among adults of reproductive age ranged from $0.2 \%$ to $26.5 \%$ (average $4.9 \%$, SD $6.5 \%$ ). The average literacy and poverty rates were $65 \%$ and $47 \%$, respectively. Contraceptive use was reported for $28 \%$ of women; $59 \%$ of all deliveries were reported to be supervised by a skilled healthcare provider. An average of six health professionals cared for a population of 10000 . US\$209.6 was spent on health per person per year with a wide disparity ranging from US $\$ 17$ to US $\$ 1642$ per person per year. Only eight countries (Botswana, Equatorial Guinea, Gabon, Mauritius, Seychelles, Swaziland, South Africa and Namibia) spent up to US\$250 per person per year, the rest committed $<\mathrm{US} \$ 100$ per person per year. Quality of healthcare governance was low with an average of -4.1. Only the Seychelles, Mauritius, Cape Verde, Namibia, Botswana, Ghana and South Africa had a positive healthcare governance score.

\section{Special-cause and common-cause variations in neonatal mortality}

Figure 1 shows the results of the control chart that explored variation in neonatal mortality across 49 SSA countries. The weighted mean of neonatal mortality rates was 29.8 per 1000 live births. Neonatal mortality rates in
21 SSA countries $(43 \%)$ were within the $99.8 \%$ control limits. Variation observed within this limits suggests common-cause variation. Neonatal mortality rates in 14 SSA countries were above and in 14 countries below the $99.8 \%$ control limits, indicating special-cause variation in $28(57 \%)$ SSA countries.

\section{Geographical variation/clustering in neonatal mortality}

Table 2 shows both global and local spatial autocorrelation for neonatal mortality among SSA countries. The global Moran's I statistic (Moran's I statistic $=-0.0925$; $\mathrm{p}=0.74$ ) and Geary's C statistic (Geary's C statistic $=1.0640$; $\mathrm{p}=0.71$ ) were not significant indicating absence of spatial clustering of neonatal mortality rates. The local spatial autocorrelation estimates for neonatal mortality were similarly not significant indicating absence of local spatial autocorrelation between any SSA country and neighbouring countries.

\section{Associations between country-level characteristic and neonatal mortality}

The relationships between country-level characteristics (HIV prevalence, health financing, health human resources, health service delivery, health governance and country socioeconomic status) and neonatal mortality are shown in figure 2. No relationship was 
Table 3 Association between prespecified country characteristics and neonatal death

\begin{tabular}{lll}
\hline Country characteristics & Univariable model & Multivariable model \\
\hline HIV prevalence & $\beta(95 \% \mathrm{Cl})$ & $\beta(95 \% \mathrm{Cl})$ \\
Health financing & $0.019(-0.429$ to 0.467$)$ & $0.463(0.135 \text { to } 0.790)^{\star \star}$ \\
Health human resources & $-0.011(-0.020 \text { to }-0.002)^{\star}$ & $\# \# \#$ \\
Health service delivery & $-5.962(-8.870 \text { to }-3.055)^{\star \star \star}$ & $\# \# \#$ \\
Health governance & $-0.290(-0.422 \text { to }-0.158)^{\star \star \star}$ & $\# \# \#$ \\
Country socioeconomic index & $-1.707(-2.282 \text { to }-1.133)^{\star \star \star}$ & $-1.327(-2.073 \text { to }-0.580)^{\star \star}$ \\
\hline
\end{tabular}

${ }^{*} \mathrm{p}<0.05 ;{ }^{* *} \mathrm{p}<0.01 ;{ }^{* \star *} \mathrm{p}<0.001 ; \beta$ regression coefficient, \#\#\# variable omitted in the final model based on adjusted $\mathrm{R}^{2}$.

observed between HIV prevalence among the population of reproductive age and neonatal mortality. HIV prevalence rates were lowest for Cape Verde, Mauritania, Madagascar, Niger, Senegal and Somalia and highest for Swaziland, Lesotho, Botswana, South Africa, Zimbabwe and Namibia. In general, neonatal mortality was inversely related to healthcare financing, health human resource capacity, coverage of health service delivery quality of healthcare governance and socioeconomic index of the country.

Further quantitative assessment of relationships between country characteristics and neonatal mortality using two-way scatter plots with a prediction line and 95\% CI showed no relationship between HIV prevalence and neonatal mortality (figure 3). Financial investment in health was inversely related to neonatal mortality (correlation coefficient $\mathrm{r}=0.35 ; \mathrm{p}=0.01$ ). Similarly, country's health human resources capacity showed an inverse linear relationship with neonatal mortality (correlation coefficient $r=0.52 ; p<0.001$ ). An inverse relationship was observed between the population coverage of health service delivery and neonatal mortality (correlation coefficient $\mathrm{r}=0.54 ; \mathrm{p}<0.001$ ). As country's quality of healthcare governance increased neonatal mortality decreased (correlation coefficient $\mathrm{r}=0.52 ; \mathrm{p}<0.001$ ); a similar relationship was observed for socioeconomic index (correlation coefficient $\mathrm{r}=0.61 ; \mathrm{p}<0.001$ ). The pooled characteristics (HIV prevalence, health financing, health human resources, health service delivery, quality of healthcare governance and country socioeconomic index) of the countries below, within and above the control limits ( $\approx 3 \mathrm{SD}$ ) were compared with average neonatal mortality using multiple double-bar charts as shown in figure 4 . The results clearly show linear inverse relationships of the country's health financing, health human resources, health service delivery coverage, health governance performance and socioeconomic index with neonatal mortality. HIV prevalence appeared not to have a significant relationship with neonatal mortality.

The results of the linear regression analysis to examine the association between country characteristic and neonatal death are shown in table 3. In the multivariable regression model, three country characteristics were observed to have a significant independent association with neonatal death. The quality of healthcare governance was the strongest underlying factor for neonatal survival; for every unit increase in country's quality of healthcare governance neonatal mortality declined by -1.327 per 1000 live births $(95 \%$ CI -2.073 to $-0.580 ; \mathrm{p}<0.01)$. In addition, for every unit decline in the percentage of population under socioeconomic deprivation, neonatal mortality declined by -0.234 per 1000 live births $(95 \%$ CI -0.424 to $-0.044 ; \mathrm{p}<0.05)$, whereas for every unit increase in the prevalence of HIV/AIDS among the population of reproductive age, neonatal mortality increased by 0.463 per 1000 live births $(95 \%$ CI 0.135 to $0.790 ; \mathrm{p}<0.01)$.

\section{DISCUSSION}

This study shows a vast geographical variation in neonatal mortality across 49 SSA countries. A substantial part of this variation could be explained by the differences in quality of healthcare governance, prevalence of HIV among the population of reproductive age and socioeconomic index across SSA countries. Even though we applied the appropriate statistical methods for analysis and the data used can be perceived as reliable data considering their sources, our findings could be threatened by ecological fallacy; this seems, however, to be very unlikely for the observed relationship between the quality of healthcare governance and neonatal death. Residual confounding might have influenced the observed relationships as individual-level characteristics could not be considered. In addition, the temporal relationship between neonatal mortality and country characteristics could not be established in this type of study. Thus, it is impossible to make a causal inference. Our study showed that in this region, more than half of the residents are living in poverty, 1 out of 20 people is HIV-infected and the scarcity of human and financial resources makes it difficult to provide adequate health services and other basic necessities of life such as safe water and education. Our analyses do not show spatial clustering in neonatal mortality among SSA countries. This spatial randomness might be due to the use of data at country-level rather than at province or district 
level as employed in previous studies observing spatial clustering in childhood mortality and morbidity. ${ }^{78}$ The control chart analyses showed both common-cause and special-cause variation in neonatal mortality. Further examination of countries located below the control limits may identify factors that explain why these countries perform better than others. Similarly, countries above the control limits ( $>3 \mathrm{SD}$ ) should be thoroughly assessed to identify factors responsible for their excess incidence of neonatal mortality. While countries within the $99.8 \%$ control limits show no evidence of specialcause variation, it remains to be explained why they have higher neonatal mortality rate than those below the control limits.

Globally, the leading direct causes of neonatal deaths are: prematurity/lowbirth weight, birth asphyxia, neonatal sepsis and birth trauma. ${ }^{1}$ Indirect factors also contribute to neonatal death by influencing neonatal survival at both individual level and population level. ${ }^{30}$ The present study investigated the associations between neonatal mortality and indirect factors by identifying differences in country characteristics that might be responsible for the observed variations in neonatal mortality in SSA. Quality of healthcare governance was the strongest determinant of neonatal mortality in this study, although only 7 of the 49 SSA countries showed a positive rating in the quality of healthcare governance. To date, no previous studies in the literature have linked the quality of healthcare governance with neonatal mortality. Generally, emphasis has been placed on increasing health financing and health service coverage which is commendable, but only in the presence of good healthcare governance can this be fully effective. Without ensuring good quality in healthcare governance, scarce healthcare resources will not be used judiciously as shown by the results of a diagnostic public expenditure tracking survey conducted in Ghana, Uganda and Tanzania that demonstrated extensive leakages of public funds in these three SSA countries. ${ }^{31}$ Thus, genuine commitment by governments is required to improve the quality of healthcare governance by ensuring transparency and accountability, government effectiveness, political stability, adherence to the rule of law, high regulatory quality and stiffer disciplinary action against corruption.

HIV prevalence among the population of reproductive age was positively associated with neonatal death, consistent with findings from a previous study that showed that neonates of HIV-positive mothers were more likely to die. ${ }^{32}$ This is yet another argument to promote prevention of mother-to-child transmission. Neonatal mortality declined as country's socioeconomic index improved, a result in line with previous studies observing that dwelling in a socioeconomically deprived population increases the risk of childhood morbidity and mortality. ${ }^{30} 33-35$ Similarly, a multicountry study that involved 13 SSA countries showed that the likelihood of dying at neonatal stage among the families in the poorest quintile was almost $70 \%$ higher than in the richest quintile. ${ }^{36}$ Implementing free basic education and poverty alleviation programme in conjunction with expansion of safe water supply and promotion of effective sanitation programme will help to improve neonatal survival. In conclusion, the results of this study based on data from 49 SSA countries show a marked variation in neonatal mortality. A substantial part of this variation can be explained by differences in health governance performance, prevalence of HIV and socioeconomic deprivation.

\section{Author affiliations}

${ }^{1}$ Julius Global Health, Julius Center for Health Sciences and Primary Care, University Medical Centre Utrecht, Utrecht, The Netherlands

${ }^{2}$ International Research Centre of Excellence, Institute of Human Virology, Abuja, Nigeria

${ }^{3}$ Global Geo and Health Data Center, Utrecht University, Utrecht, The Netherlands ${ }^{4}$ Postdoctoral Unit, Noguchi Memorial Institute for Medical Research, University of Ghana, Accra, Ghana

${ }^{5}$ Department of Epidemiology and Disease Control, School of Public Health, University of Ghana, Accra, Ghana

${ }^{6}$ Research and Development Division, Ghana Health Service, Accra, Ghana ${ }^{7}$ Warwick-Centre for Applied Health Research and Delivery, Division of Health Sciences, Warwick Medical School, The University of Warwick, Coventry, UK ${ }^{8}$ International Health Group, Liverpool School of Tropical Medicine, Liverpool, UK ${ }^{9}$ Division of Epidemiology and Biostatistics, Faculty of Health Science, School of Public Health, the University of Witwatersrand, Johannesburg, South Africa

Acknowledgements The authors appreciate WHO and World Bank for making their data available to the public.

Contributors GAK, KK-G and DEG conceptualised and designed the study. GAK carried out the literature review, data extraction, analysis, result interpretation and drafted the first version of the manuscript. OAU contributed to the analysis. All the authors reviewed and approved the final version of the manuscript.

Funding GAK and MAC received financial support from the Netherlands Organization for Scientific Research to complete their PhD training.

Competing interests None declared.

Provenance and peer review Not commissioned; externally peer reviewed.

Data sharing statement The authors used publicly available data from WHO, the US Agency for International Development and the World Bank.

Open Access This is an Open Access article distributed in accordance with the terms of the Creative Commons Attribution (CC BY 4.0) license, which permits others to distribute, remix, adapt and build upon this work, for commercial use, provided the original work is properly cited. See: http://creativecommons.org/ licenses/by/4.0/

(c) Article author(s) (or their employer(s) unless otherwise stated in the text of the article) 2017. All rights reserved. No commercial use is permitted unless otherwise expressly granted.

\section{REFERENCES}

1. Newborns: reducing mortality. http://www.who.int/mediacentre/ factsheets/fs333/en/ (accessed 15 Jan 2015).

2. Martines J, Paul VK, Bhutta ZA, et al. Neonatal survival: a call for action. The Lancet 2005;365:1189-97.

3. Oestergaard MZ, Inoue M, Yoshida S, et al. Neonatal mortality levels for 193 countries in 2009 with trends since 1990: a systematic analysis of progress, projections, and priorities. PLoS Med 2011;8:e1001080.

4. Hill K, Choi Y. Neonatal mortality in the developing world. Demogr Res 2006;14:429-52.

5. Lawn JE, Cousens S, Zupan J. Lancet neonatal survival steering team. 4 million neonatal deaths: when? Where? Why? Lancet 2005;365:891-900.

6. Maternal and newborn health. http://www.unicef.org/health/index maternalhealth.html (accessed 17 Jan 2015). 
7. Adekanmbi VT, Uthman OA, Mudasiru OM. Exploring variations in childhood stunting in Nigeria using league table, control chart and spatial analysis. BMC Public Health 2013;13:361.

8. Uthman OA, Aiyedun V, Yahaya I. Exploring variations in under-5 mortality in Nigeria using league table, control chart and spatia analysis. J Public Health 2012;34:125-30.

9. Glance LG, Osler TM, Dick A. Rating the quality of intensive care units: is it a function of the intensive care unit scoring system? Crit Care Med 2002;30:1976-82.

10. Marshall EC, Spiegelhalter DJ. Reliability of league tables of in vitro fertilisation clinics: retrospective analysis of live birth rates. $B M J$ 1998;316:1701 -4.

11. Aylin P, Alves B, Best N, et al. Comparison of UK paediatric cardiac surgical performance by analysis of routinely collected data 1984-96: was Bristol an outlier? The Lancet 2001;358:181-7.

12. Scally G, Donaldson LJ. The NHS's 50 anniversary. Clinical governance and the drive for quality improvement in the new NHS in England. BMJ 1998;317:61-5.

13. Stuart M, Mullins E, Drew E. Statistical quality control and improvement. Eur J Oper Res 1996;88:203-14.

14. Ipek $\mathrm{H}$, Ankara $\mathrm{H}$, Ozdag $\mathrm{H}$. The application of statistical process control. Minerals Engineering 1999;12:827-35.

15. Mason MJ, Moran JW. Understanding and Controlling Variation in Public Health. Journal of Public Health Management and Practice 2012;18:74-8.

16. Siriwardena AN, Balestracci D. Using a common cause strategy for quality improvement: improving hypnotic prescribing in general practice within a quality improvement collaborative. Qual Prim Care 2011;19:283-7.

17. Cheung YT, Spittal MJ, Pirkis J, et al. Spatial analysis of suicide mortality in Australia: investigation of metropolitan-rural-remote differentials of suicide risk across states/territories. Soc Sci Med 2012;75:1460-8.

18. Jerrett M, Burnett RT, Ma R, et al. Spatial analysis of air pollution and mortality in Los Angeles. Epidemiology 2005;16:727-36.

19. Key facts on HIV epidemic and progress in regions and countries in 2010. [http://www.who.int/hiv/pub/progress_report2011/regional facts/en/] (accessed 23 Jan 2015).

20. Prevention of mother-to-child transmission of HIV/AIDS programmes. http://www.who.int/pmnch/media/publications/ aonsectionllI_7.pdf (accessed 7 Feb 2015).

21. Global health observatory data repository. http://apps.who.int/gho/ data/node.main (accessed 7 Feb 2015).
22. Health sytem report. https://www.hfgproject.org/resources/healthsystems-database/country-profiles/ (accessed 14 Feb 2015).

23. World Bank Open Data. http://data.worldbank.org/ (accessed 7 Jan 2015)

24. Health governance. Concepts, experience, and programming options. https://www.hfgproject.org/wp-content/uploads/2015/ 02/Health-Governance-Concepts-Experience-and-ProgrammingOptions.pdf (accessed 11 Jan 2015).

25. R: a language and environment for statistical computing. http://www. R-project.org/ (accessed 28 Jan 2015).

26. Stata statistical software version 11. www.stata.com (accessed 6 Mar 2015).

27. Pfeiffer D, Robinson T, Stevens K, et al. Clements a: spatial analysis in epidemiology. Oxford university press: oxford, 2008

28. Anselin L. Local Indicators of Spatial Association-LISA. Geogr Anal 1995;27:93-115.

29. Anselin L, Bera A. Spatial dependence in linear regression models with an introduction to spatial econometrics. Handbook of applied economic statistic. New york: Marcel Dekker.

30. Kayode GA, Ansah E, Agyepong IA, et al. Individual and community determinants of neonatal mortality in Ghana: a multilevel analysis. BMC Pregnancy Childbirth 2014;14:165.

31. Assessing frontline service delivery. http://www1.worldbank.org/ publicsector/anticorrupt/reinikka_assessingfrontline.pdf (accessed 9 Jan 2015).

32. Ryder RW, Nsa W, Hassig SE, et al. Perinatal Transmission of the Human Immunodeficiency Virus Type 1 to Infants of Seropositive Women in Zaire. N Engl J Med Overseas Ed 1989;320:1637-42.

33. Kayode GA, Amoakoh-Coleman M, Agyepong IA, et al. Contextual Risk Factors for Low Birth Weight: A Multilevel Analysis. PLoS One 2014;9:e109333.

34. Adekanmbi VT, Kayode GA, Uthman OA. Individual and contextual factors associated with childhood stunting in Nigeria: a multilevel analysis. Matern Child Nutr 2013;9:244-59.

35. Macro O. StatCompiler DHS. http://www.statcompiler.com/ (accessed 21 Mar 2015).

36. Opportunities for Africa's newborns: practical data, policy and programmatic support for newborn care in Africa. http://www.who.int/pmnch/media/publications/oanfullreport.pdf (accessed 14 Jan 2015) 